\title{
Need for Prophylactic Treatment in Adult Haemophilia A Patients
}

\author{
Berthold Siegmund Heinrich Richter Hartmut Pollmann \\ Institut für Thrombophilie und Hämostaseologie, Münster, Germany
}

\section{Key Words \\ Haemophilia A · On-demand therapy · Continuous prophylaxis}

\section{Summary}

Background and Methods: A single centre study including 52 German patients aged $\geq 16$ years with severe haemophilia A was performed to compare the amount of clotting factor and outcome between on-demand therapy (26 patients) and continuous prophylaxis (26 patients) over 1 year. Results: Prophylaxis reduced the number of bleeds significantly. Compared to on-demand treatment $(20.5 \pm 3.0 \mathrm{bleeds/year/patient})$, under prophylaxis $7.8 \pm 1.3$ bleeds/year/patient were observed. Joint bleeds were reduced from $12.2 \pm 1.5$ to $4.7 \pm 1.0$ /year/ patient. In the on-demand group $38 \%$ of the patients suffered from more than 2 bleeds/month, whereas in the prophylaxis group no patient was found with more than 2 bleeds/month. Mean annual factor VIII (FVIII) consumption increased from $767 \pm 110 \mathrm{IU} / \mathrm{kg}$ body weight under on-demand treatment to $2,841 \pm 341 \mathrm{IU} / \mathrm{kg}$ body weight under continuous prophylaxis, displaying a nearly fourfold increase in FVIII consumption. Furthermore, prophylaxis implies a more than four-fold increase in treatment days which escalated from a mean weekly injection rate of $0.56 \pm 0.08 \mathrm{FVIII}$ injections/week when bleeds were treated on demand to $2.52 \pm 0.30 \mathrm{FVIII}$ injections/week during prophylaxis. Conclusion: Even though the results reflect a benefit also for prophylactically treated patients regarding their bleeding frequency, one has to take into account a substantial increase of the costs for coagulation concentrates when all patients with severe haemophilia A switch to continuous prophylaxis.

\author{
Schlüsselwörter \\ Hämophilie A · Bedarfstherapie · Prophylaxe
}

\section{Zusammenfassung}

Hintergrund und Methoden: In einer retrospektiven Studie eines deutschen Behandlungszentrums wurden Nutzen und Aufwand einer prophylaktischen Substitutionstherapie im Vergleich zur Bedarfsbehandlung an jeweils 26 Patienten $\geq 16$ Jahre mit schwerer Hämophilie A über einen Vergleichszeitraum von 1 Jahr ermittelt. Ergebnisse: Die Prophylaxe reduzierte die Anzahl der Blutungen von $20,5 \pm 3,0$ auf 7,8 $\pm 1,3 / \mathrm{Jahr} /$ Patient. Gelenkblutungen verminderten sich von 12,2 $\pm 1,5$ auf $4,7 \pm 1,0$ / Jahr/Patient. Unter Bedarfsbehandlung erlitten 38\% der Patienten mehr als 2 Blutungen/Monat, unter Prophylaxe fand sich kein Patient mehr mit mehr als 2 Blutungen/ Monat. Der mittlere Jahresverbrauch an Faktor VIII (FVIII) stieg im Vergleich zur Bedarfsbehandlung $(767 \pm 110$ Einheiten/kg Körpergewicht) um zirka das Vierfache auf $2841 \pm 341$ Einheiten/kg Körpergewicht an. Die wöchentliche Injektionsrate von FVIII erhöhte sich im Mittel von $0,56 \pm 0,08$ auf $2,52 \pm 0,30$. Schlussfolgerung: Auch wenn anhand dieser Ergebnisse der Nutzen einer prophylaktischen Substitutionstherapie auch für das Erwachsenenalter gegeben zu sein scheint, ist zu bedenken, dass der steigende Jahresbedarf an FVIII-Gerinnungskonzentraten und die damit verbundenen Präparatekosten wesentlich zunehmen, wenn alle Patienten mit schwerer Hämophilie A auf eine kontinuierliche Prophylaxe wechseln.

\begin{tabular}{ll}
\hline KARGER & @ 2009 S. Karger GmbH, Freiburg \\
Fax +497614520714 & $\begin{array}{l}\text { Accessible online at: } \\
\text { www.karger.com/tmh }\end{array}$ \\
$\begin{array}{l}\text { Information@Karger.de } \\
\text { www.karger.com }\end{array}$ &
\end{tabular}




\section{Introduction}

Haemophilia A is a congenital bleeding disorder caused by an X-chromosome linked deficiency in coagulation factor VIII (FVIII) [1-3]. Treatment of haemophilia A is based on intravenous administration of an appropriate dose of external FVIII either on a preventative basis (continuous prophylaxis) or episodically, i.e. when bleeding episodes have been occurred (on-demand therapy). Self-treatment at home is the rule in Germany and is performed successfully by the majority of haemophiliacs, thus reducing the need to visit a physician or haemophilia centre for injection of FVIII concentrate.

Younger haemophilia A patients in particular are often provided with coagulation factor products at regular intervals of 2-3 injections/week on a continuous basis. The intention of this therapeutic strategy of continuous prophylaxis is the avoidance of frequent bleeds, especially joint bleeds, in order to prevent the development of a target joint. The benefits of continuous prophylaxis have been demonstrated in several studies [4-6]. It is considered the optimal treatment for children with severe haemophilia (FVIII $<1 \%$ ) and has been recommended for children for more than a decade by the WHO [7]. However, continuous prophylaxis is not restricted only to younger patients and may also be beneficial to adults. Even if prevention of a target joint is not the main concern for older haemophiliacs, continuous prophylaxis may be expedient in relieving the burden of frequent bleeds and improving quality of life [8-11]. Therefore, the aim of the present study is to evaluate the effect of secondary continuous prophylaxis compared to on-demand therapy in older patients with severe haemophilia A, with the emphasis on bleeding events and the amount of FVIII required. The resulting data will provide an answer to the question posed in MASC recommendation 170 from 2006 [12] 'what can reasonably be expected from prophylaxis' with reference to prophylaxis for older children, adolescents, and adults. We will report on our experience of haemophilia A patients $\geq 16$ years either treated on demand or preventatively in the home care setting.

\section{Material and Methods}

The study presented here was performed as a retrospective, observational, single centre study in a centre for diagnosis and therapy of bleeding disorders (Praxis für Diagnostik und Therapie von Blutgerinnungsstörungen Dr. med. H. Pollmann, Ambulanzzentrum an der Raphaelsklinik, Münster, Germany) within the collective of its haemophilia A patients. Only patients with severe haemophilia A $(<0.01 \mathrm{U} / \mathrm{ml}$ FVIII activity) were included. Data were analysed over the year 2005.

The study was performed with the approval of the local ethics committee; all patients signed a written informed consent and agreed to provide data for statistical purposes. After being trained, all patients injected themselves the FVIII concentrates in the home care setting. In order to comply with the regulations of the German Transfusion Law (Transfusionsgesetz), which regulates the obligation to document the use of blood products and their recombinant derivatives, patients are requested to doc- ument each individual infusion in a paper-based diary. Amongst others, the date when FVIII was administered, dosage and brand name of the product were recorded together with the location of the bleed and the treatment regimen. Data on bleeding episodes and treatment were extracted from these diary records for further analysis. Documentation of bleeds and treatment by the patients was almost complete; over $99 \%$ of the amount of FVIII prescribed was recorded in the patients' diaries.

Analyses were performed separately for each patient, i.e. therapy regime, number and location of the bleeds, number of injections, and amount of coagulation factor administered required for controlling a bleed. We analysed and compared results for those haemophilia A patients attending our centre who were aged $\geq 16$ years and did not have any further coagulation disorders. They were treated either on demand after bleeding episodes occurred (on-demand treatment, group $1, \mathrm{n}=26$ ) or continuously in order to prevent bleeding episodes (prophylaxis, group $2, \mathrm{n}=26$ ). Complete documentation over the year 2005 of all bleeds and infusions was a prerequisite for inclusion into the study. Mixed regimens, i.e. patients who switched from on-demand treatment to prophylaxis or vice versa during the observation period, were not included. Data are given as mean values \pm SEM

\section{Results}

\section{Patients and Treatment Characteristics}

Out of the collective of patients with severe haemophilia A at our treatment centre, 52 patients agreed to participate in this study and fulfilled the inclusion criteria. Within the study group, 26 patients were treated on demand, and an equal number of patients underwent continuous prophylaxis for the complete observation period of 2005. Patients had a mean age of $33.3 \pm 3.7$ years and $27.7 \pm 3.2$ years $(p=0.26)$ in the ondemand and prophylaxis groups, respectively. The mean body weight of the patients was $78.3 \pm 8.4 \mathrm{~kg}$ in the on-demand group and $71.1 \pm 7.2 \mathrm{~kg}$ in the prophylaxis group $(\mathrm{p}=0.52)$. During the observation period a total of $6,839,300$ IU FVIII was prescribed by the treating physician, and an amount of $6,772,250$ IU FVIII ( $>99 \%$ of the prescribed FVIII amount) was documented by the patients in their diaries so that an almost complete documentation can be assumed (table 1).

The FVIII doses prescribed and the treatment frequency were based on the amounts recommended by the National Chamber of German Physicians [13], but were adjusted to the individual needs of the patients. The prescribed amount of FVIII/infusion averaged $26.9 \pm 2.7$ (range 17.7-33.9) IU/kg body weight and $22.2 \pm 2.4$ (6.4-35.7) IU/kg body weight for the on-demand and prophylaxis groups, respectively.

The frequency of replacements for the individual patients recommended by the physician for continuous prophylaxis varied between 1-7 injections/week. On average, all patients were advised to perform $2.9 \pm 1.9$ injections/week for prophylaxis. Two patients were advised to inject once a week, 11 patients were advised to inject twice a week, 10 patients were advised to inject 3 times a week, and 3 patients 7 times a week. As calculated from the patients' diaries, the effective prophylactic replacements documented in 2005 resulted in a frequency of $2.52 \pm 0.30$ injections/week. The patients 
Table 1. Patients' characteristics

\begin{tabular}{lcc}
\hline & OD & CP \\
\hline Mean age, years & $33.3 \pm 3.7$ & $27.7 \pm 3.2$ \\
Mean body weight, kg & $78.3 \pm 8.4$ & $71.1 \pm 7.2$ \\
Number of patients treated with pdFVIII (\%) & $13(25 \%)$ & $11(21 \%)$ \\
Number of patients treated with rFVIII (\%) & $13(25 \%)$ & $15(29 \%)$ \\
Amount of FVIII prescribed, IU & $6,839,300$ \\
Amount of FVIII documented, IU & $6,772,250(99 \%)$ \\
\hline
\end{tabular}

Fig. 1. Number of bleeding episodes per year (joint bleeds, non-joint bleeds, non-allocated bleeds) during on-demand treatment (left column) and continuous prophylaxis (right column), means \pm SEM, $\mathrm{n}=26$ patients in each group.

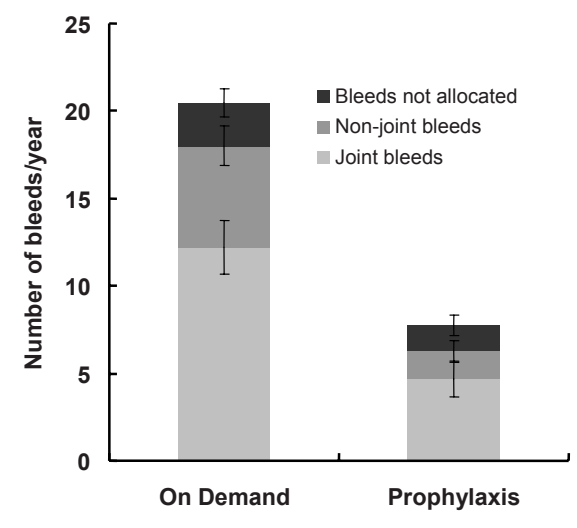

following the on-demand regimen recorded on average 0.56 \pm 0.08 replacement injections/week.

Patients were treated with different FVIII concentrates - plasma-derived (pdFVIII) as well as recombinant products (rFVIII). A total of 24 patients (46\%) received plasma-derived products, and 28 patients $(54 \%)$ received recombinant products (table 1).

\section{Outcome, Bleeds and Treatment of Bleeds}

During the observation period, a total of 734 bleeding episodes were recorded by the 52 patients. The 26 patients being treated on demand experienced a total of 532 bleeds $(20.5 \pm$ $3.0(0-58)$ bleeds/patient), and the 26 patients being treated with continuous prophylaxis documented 202 bleeds $(7.8 \pm$ 1.3 (0-22) bleeds/patient). On-demand patients described 317 (59.6\% of total bleeds) bleeds as joint bleeds while 121 bleeds (59.9\% of total bleeds) were documented as joint bleeds in the continuous prophylaxis group. Non-joint bleeds were reported 151 times by patients being treated on demand while patients on continuous prophylaxis experienced only 42 nonjoint bleeds. A total of 64 bleeds in patients receiving on-demand treatment and 39 bleeds in patients on prophylaxis were not allocated in the patients' diaries to a specific location in the body (fig. 1). The reduction in bleeds, with the exception of non-allocated bleeds, was statistically significant.

To control a single bleed, on average $1.46 \pm 0.16$ days with FVIII injections ('injection days') were needed during on-demand treatment. Treatment was slightly but not significantly prolonged in the case of continuous prophylaxis to $1.75 \pm 0.22$ days of FVIII injections $(\mathrm{p}=0.2695)$. Bleeds were treated in the on-demand group and in the continuous prophylaxis group on average $2.6 \pm 0.8 \mathrm{~h}$ and $1.6 \pm 0.7 \mathrm{~h}$ after they were noticed, respectively $(\mathrm{p}=0.4282)$. Of course, continuous prophylaxis resulted in a rise in the total number of intravenous injections $(2.52 \pm 0.30 /$ week/patient $)$ when compared with on-demand patients $(0.56 \pm 0.08 /$ week/patient $)(\mathrm{p}<0.0001)$.

Patients displayed a wide range of different bleeding profiles, and the number of bleeds caused by haemophilia A varied considerably between the patients. In the case of ondemand treatment a range of 1 to 58 bleeds/year/patient was observed. Between 0 and 22 bleeds/year/patient were noticed in patients on continuous prophylaxis. Therefore, to illustrate the beneficial effect of prophylaxis, we classified the patients into three categories according their number of bleeding episodes: patients with no bleeds (0 bleeds/month), patients with few bleeds (1-2 bleeds/month), and patients with frequent bleeds ( $>2$ bleeds/month). Comparing on-demand treatment regimen with prophylaxis, the number of patients experiencing no bleeds increased from 0 to 3 and the number of patients with only a few bleeds increased from 16 to 23 , whereas the number of patients with frequent bleeds decreased from 10 to 0 . In other words, prophylaxis caused an alteration of 10 out of 26 patients (38\%) from the category 'frequent bleeds' to the category 'few or no bleeds', i.e. thanks to prophylaxis more patients bleed less (table 2).

During the observation period a total of 6,772,250 IU FVIII was used by all patients. During 2005, the 26 patients being treated on demand applied 1,543,000 IU FVIII (59,346 $\pm 8,503$ (2,000-162,000) IU/patient, equalling $767 \pm 110 \mathrm{IU} / \mathrm{kg}$ body weight). The 26 patients on prophylaxis applied 5,229,250 IU FVIII $(201,125 \pm 26,349(48,000-711,000)$ IU/patient, i.e. 2,841 $\pm 341 \mathrm{IU} / \mathrm{kg}$ body weight). During the observation period on-demand patients had additional prophylactic injections of FVIII ( $24 \pm 10 \mathrm{IU} / \mathrm{kg}$ body weight, equalling $3.1 \%$ of the total value of $767 \pm 110 \mathrm{IU}$ ) for specific reasons, i.e. visits to a dentist. Patients on continuous prophylaxis needed $379 \pm 68$ IU/kg body weight FVIII to control acute bleeds, and 2,463 \pm $304 \mathrm{IU} / \mathrm{kg}$ body weight FVIII were needed for prophylactic infusions (fig. 2).

Continuous prophylaxis was associated with a large increase in the number of days when patients had to self-inject. Patients in the on-demand group needed 762 injections $(29.3$ \pm 4.1 injections/patient) per year, whereas patients on prophylaxis had a total of 3,410 days with a FVIII injection (131.2 \pm 16.9 injections/patient). In the on-demand group, patients recorded 738 infusions to treat bleeding episodes $(28.4 \pm 4.0$ injections/patient) and additionally 24 prophylactic FVIII infusions $(0.9 \pm 0.4$ injections/patient $)$. Patients on continuous prophylaxis injected FVIII 346 times $(13.3 \pm 2.3$ injections/patient) in response to a bleeding episode and 3,064 times (117.9 \pm 15.7 injections/patient) as part of the prophylactic treatment regimen (table 2 ). 
Table 2. Bleeding and treatment parameters of patients with severe haemophilia $\mathrm{A}$ in the on-demand group (OD) and in the continuous prophylaxis group $(\mathrm{CP})$ in the observation period of 1 year

\begin{tabular}{llll}
\hline & $\begin{array}{l}\text { OD } \\
(\mathrm{n}=26)\end{array}$ & $\begin{array}{l}\text { CP } \\
(\mathrm{n}=26)\end{array}$ & p value \\
\hline FVIII consumption per year, IU & $1,543,000$ & $5,229,250$ & \\
Number of infusions/bleed & $1.5 \pm 0.2$ & $1.8 \pm 0.2$ & 0.2695 \\
Treatment delay after recognition of the bleed, $\mathrm{h}$ & $2.6 \pm 0.8$ & $1.6 \pm 0.7$ & 0.4282 \\
Mean weekly FVIII injection rate/patient & $0.56 \pm 0.08$ & $2.52 \pm 0.30$ & 0.0001 \\
Bleeding classification & & & \\
$\quad$ Number of patients with no bleeds/month) $(\%)$ & $0(0 \%)$ & $3(12 \%)$ & \\
$\quad$ Number of patients with 1-2 bleeds/month (\%) & $16(62 \%)$ & $23(88 \%)$ & \\
$\quad$ Number of patients with >2 bleeds/month (\%) & $10(38 \%)$ & $0(0 \%)$ & \\
Days with FVIII infusion per patient and year & & & \\
$\quad$ Total number of days & $29.3 \pm 4.1$ & $131.2 \pm 16.9$ & 0.0001 \\
$\quad$ Number of days to treat acute bleeds & $28.4 \pm 4.0$ & $13.3 \pm 2.3$ & 0.0022 \\
$\quad$ Number of days with prophylactic treatment & $0.9 \pm 0.4$ & $117.9 \pm 15.7$ & 0.0001 \\
\hline
\end{tabular}

\section{Inhibitor Development}

An inhibitor against FVIII was not developed in both patient groups.

\section{Discussion}

The results clearly demonstrate the ability of continuous prophylaxis to reduce the burden of bleeds for haemophilia patients. In the present study, patients receiving prophylaxis experienced $62 \%$ fewer bleeding episodes compared to patients receiving on-demand treatment. This reduction of the bleeding frequency applies to joint haemorrhages as well as to haemorrhages of the soft tissue. It is in good agreement with other previously published studies [5, 14-18, for review see 19, 20].

Under the protection of continuous prophylaxis still a relatively high number of joint bleeds were observed, $59.9 \%$ of all bleeding episodes were described as joint bleeds by the patients. It is assumed that this collective of preventatively treated patients comprises patients which are more susceptible for bleeds into their joints. In particular those patients were switched by the physician to prophylaxis, which are conspicuous by frequent and/or severe bleeds in their bleeding history and which are jeopardised to develop a target joint.

In our haemophilia centre, young patients suffering from haemophilia A are initially treated on demand, but the therapy regime will be changed to continuous prophylaxis when bleeding episodes accumulate. But not every patient is switched to continuous prophylaxis during the course of his life. Sometimes the bleeding pattern of a patient justifies a continuation of the on-demand regimen. The decision to change the treatment regimen is taken by the physician in accordance with the individual patient. However, two different groups of haemophilia patients result in the elder patient population of our treatment centre: patients who were treated on demand and patients who were switched to prophylaxis prior they have reached the age of 16 years. Since the decision to start prophylaxis was made in dependence of the severity of the specific bleeding pattern of the patient, anamnesis of
Fig. 2. Consumption of FVIII/year under on-demand regimen (left column) versus continuous prophylaxis (right column) for the treatment of acute bleeds and for prophylactic injections, means \pm SEM, $\mathrm{n}=26$ patients in each group.

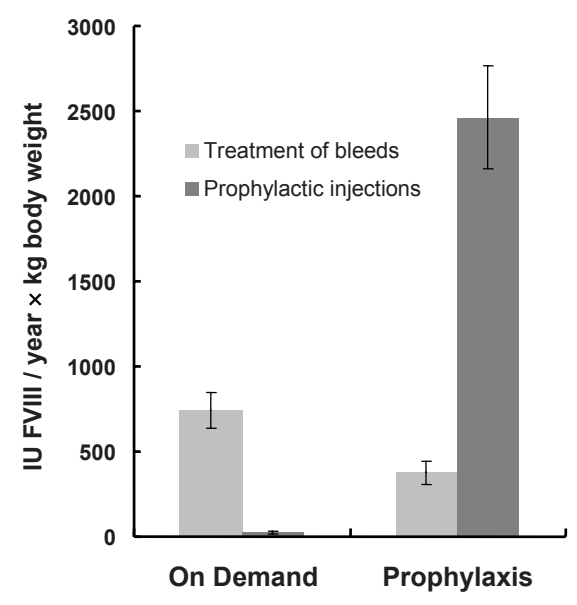

the patients in the on-demand and in the prophylaxis group is not equal. Consequently, this fact automatically results in a bias of underestimation. When assessing the effect of prophylaxis, one has to keep in mind that the 'real protective effect' of prophylaxis is presumable higher than the presented data reflect.

Prophylaxis was performed in the study population (age $\geq 16$ years) with $2.5 \pm 0.3$ injections/week and $22 \pm 2$ IU FVIII per injection on average. It corresponds closest to a regimen called 'intermediate prophylaxis' (15-25 IU/kg body weight 2 or 3 times a week) and is less than a full-dose or high-dose prophylaxis defined as the infusion of $25-40 \mathrm{IU} / \mathrm{kg}$ body weight FVIII at least three times a week $[15,21]$.

Fischer et al. [21] compared intermediate prophylaxis with high-dose prophylaxis in respect of their beneficial effects and reported 2.5 and 0.5 joint bleeds/year for intermediate and high-dose prophylactic treatment, respectively. Although the investigated patients in this study were somewhat younger, the data correlates very well with those of the present study (1.6 joint bleeds/year under prophylaxis). Similar values $(0.65$ and 0.16 bleeds/week for on-demand treatment and prophylaxis, respectively) were reported by Abshire et al. [22] in an international multicentre clinical trial with patients aged 12-60 years, and a recent prospective multicentre randomised 
trial [6] supported these results (17.7 vs. 3.3 bleeds/year/patient; mean age 1.6 years).

Nowadays continuous prophylaxis is the standard therapy regimen to treat haemophilic children, but many of the adult patients are still treated on demand. The present comparative study focuses on the question whether and to which extent prophylaxis may be also beneficial for adult patients. The study became feasible because children remained on prophylactic treatment when they grow older and reached adulthood so that more and more adult haemophiliacs now also benefit from bleeding protection by prophylaxis. Children and adolescents who are used to inject FVIII regularly do not wish to abandon the benefits of continuous prophylaxis when growing older. But the observed reduction of the number of bleeds was achieved at the expense of a higher consumption of FVIII concentrates. FVIII consumption increased by a factor of almost 4 , and of course continuous prophylaxis also escalated the encumbrance of the patients by a significantly increased frequency of intravenous injections, which increased by a factor of 4.5 . Only $10 \%$ of the FVIII injections during prophylaxis were directly caused by an acute bleed, $90 \%$ of all treatment days have to be allotted to prophylaxis.

In order to enable replacement of the missing clotting factor as soon as possible and thereby minimising the risk of a subsequent joint damage due to bleeds into the joints, practice of self-injection by the patients themselves in the home treatment setting has been successfully implemented in the past as the predominant therapeutic procedure. But it cannot be excluded that arthropathy and haemarthrosis may also develop in the adulthood even without a premature damage of the joints by bleeds in the patient's youth [23, 24]. Consequently, one has to take into consideration that prophylaxis may also be of value for older haemophiliacs. Outcome data of the orthopaedic status of our patients are not presented within this study, and to our knowledge only very limited data which elucidate the effect of secondary prophylaxis in elder patients are available in the literature. Already in 1992, Brackmann et al. [25] demonstrated in a long-term study on prophylaxis that also patients with pre-existing target joints can benefit in that joint damage was either preserved or even reduced by secondary prophylaxis.

A question remains: Since FVIII concentrate comprises approximately $90 \%$ of the total costs of haemophilia treatment [26], an economic problem may be generated if grown-up patients stay on the prophylaxis they have become accustomed to in their childhood. However, even a ballpark estimate of the costs for Germany remains speculative since the exact number of patients suffering from severe haemophilia $\mathrm{A}$ in Germany, which is estimated to be somewhere between 2,000 and 3,000, is unknown. Maybe, continuous supply with FVIII concentrates doubles the presently already high costs of haemophilia treatment. But, these costs may be (partially) balanced by reduced follow-up costs for joint replacement surgeries and early retirement from work.

An evaluation of clinical issues, health economics, and quality of life of haemophilia patients has been carried out in the ESCHQoL study [27], which is currently under analysis. Whatever the final results of this prospective study are, the ethical dilemma remains: to what extent can and should the public purse be burdened to guarantee citizens a 'normal' life free from physical impairment [28]?

In conclusion, the present study clearly demonstrates the advantage of continuous FVIII prophylaxis over on-demand treatment in haemophilia A patients. Continuous prophylaxis reduces the number of bleeding episodes significantly. However, prophylaxis cannot prevent bleeds completely and requires an almost 4-fold higher consumption of FVIII.

\section{Acknowledgement}

The authors would like to thank all participating patients for reliable documentation.

\section{Disclosure}

This study was supported as investigator originated proposal by Bayer Vital GmbH, Leverkusen, Germany.

\section{References}

1 Klinge J, Ananyeva NM, Hauser CAE, Saenko EL: Hemophilia A - from basic science to clinical practice. Semin Thromb Hemost 2002;28:309-322.

2 Hoyer LW: Hemophilia A. N Engl J Med 1994;330: 38-47.

3 Bolton-Maggs PHB, Pasi KJ: Haemophilias A and B. Lancet 2003;361:1801-1809.

4 Yee TT, Beeton K, Griffioen A, Harrington C, Miners A, Lee CA, Brown SA: Experience of prophylaxis treatment in children with severe haemophilia Haemophilia 2002;8:76-82.

5 Van Den Berg HM, Fischer K, Van Der Bom JG, Roosendaal G, Mauser-Bunschoten EP: Effects of prophylactic treatment regimens in children with severe haemophilia: a comparison of different strategies. Haemophilia 2002;8(suppl 2):43-46.
6 Manco-Johnson MJ,Abshire TC, Shapiro AD, Riske B, Hacker MR, Kilcoyne R, Ingram JD, MancoJohnson ML, Funk S, Jacobson L, Valentino LA, Hoots WK, Buchanan GR, DiMichele D, Recht M, Brown D, Leissinger C, Bleak S, Cohen A, Mathew P, Matsunaga A, Medeiros D, Nugent D, Thomas GA, Thompson AA, McRedmond K, Soucie JM, Austin H, Evatt BL: Prophylaxis versus episodic treatment to prevent joint disease in boys with severe hemophilia. N Engl J Med 2007;357:535-544.

7 Berntorp E, Boulyjenkov V, Brettler D, Chandy M, Jones P, Lee C, Lusher J, Mannucci P, Peak I, Rickard K: Modern treatment of haemophilia. Bull World Health Org 1995;73:691-701.
8 Naraine VS, Risebrough NA, Oh P, Blanchette VS, Lee S, Stain A-M, Hedden D, Teitel JM, Feldman BM: Health-related quality-of-life treatments for severe haemophilia: utility measurements using the Standard Gamble technique. Haemophilia 2002;8: 112-120.

9 Bohn RL, Schramm W, Bullinger M, Van Den Berg M, Blanchette V: Outcome measures in haemophilia: more than just factor levels. Haemophilia 2004; 10(suppl 1):2-8.

10 Bullinger M,Von Mackensen S: Quality of life assessment in haemophilia. Haemophilia 2004;10(suppl 1): 9-16.

11 Remor E, Young NL, Von Mackensen S, Lopatina EG: Disease-specific quality-of-life measurement tools for haemophilia patients. Haemophilia 2004; 10(suppl 4):30-34. 
12 Medical and Scientific Advisory Council (MASAC). MASAC Recommendation Concerning Prophylaxis (Regular Administration of Clotting Factor Concentrate to Prevent Bleeding). MASAC document \#170;2006. www.hemophilia.org/NHFWeb/Resource/StaticPages/menu0/menu5/menu57/170.pdf.

13 Bundesärztekammer: Leitlinien zur Therapie mit Blutkomponenten und Plasmaderivaten, 3. Aufl Köln, Deutscher Ärzte-Verlag, 2003. www.bundesaerztekammer.de/downloads/Blutkomponentenpdf. $p d f$.

14 Schramm W: Experience with prophylaxis in Germany. Semin Hematol 1993;30:12-15.

15 Fischer K, Astermark J, Van Der Bom JG, Ljung R, Berntorp E, Grobbee DE, Van Den Berg HM: Prophylactic treatment for severe haemophilia: comparison of an intermediate-dose to a high-dose regimen. Haemophilia 2002;8:753-760.

16 Aledort LM, Haschmeyer RH, Pettersson H: A longitudinal study of orthopaedic outcomes for severe factor-VIII-deficient haemophiliacs. The Orthopaedic Outcome Study Group. J Intern Med 1994;236 391-399.

17 Nilsson IM, Berntorp E, Lofqvist T, Pettersson H Twenty-five years' experience of prophylactic treatment in severe haemophilia A and B. J Intern Med 1992;232:25-32.
18 Pollmann H, Externest D, Ganser A, Eifrig B, Kreuz W, Lenk H, Pabinger I, Schramm W, Schwarz TF, Zimmermann R, Zavazava N, Oldenburg J, Klamroth R: Efficacy, safety and tolerability of recombinant factor VIII (REFACTO ${ }^{\circledR}$ ) in patients with haemophilia A: interim data from a postmarketing surveillance study in Germany and Austria. Haemophilia 2006;12:1-13.

19 Carcao MD, Aledort L: Prophylactic factor replacement in hemophilia. Blood Rev 2004;18:101-113.

20 Hoots WK, Nugent DJ: Evidence for the benefits of prophylaxis in the management of hemophilia A. Thromb Haemost 2006;96:433-440.

21 Blanchette VS, Mccready M, Achonu C, Abdolell M, Rivard G, Manco-Johnson MJ: A survey of factor prophylaxis in boys with haemophilia followed in North American haemophilia treatment centres. Haemophilia 2003;9(suppl 1):19-26.

22 Abshire TC, Brackmann HH, Scharrer I, Hoots K, Gazengel C, Powell JS, Gorina E, Kellermann E, Vosburgh E; the International Kogenate-FS Study Group: Sucrose formulated recombinant human antihemophilic factor VIII is safe and efficacious for treatment of hemophilia A in home therapy - International Kogenate-FS Study Group. Thromb Haemost 2000;83:811-816.
3 Battistella LR: Maintenance of musculoskeletal function in people with haemophilia. Haemophilia 1998;4(suppl 2):26-32.

24 Su Y, Wong W-Y, Lail A, Donfield SM, Konzal S, Gomperts E: Long-term major joint outcomes in young adults with haemophilia: interim data from the HGDS. The Hemophilia Growth and Development Study. Haemophilia 2007;13:387-390.

25 Brackmann HH, Eickhoff HJ, Oldenburg J, Hammerstein U: Long-term therapy and on-demand treatment of children and adolescents with severe haemophilia A: 12 years of experience. Haemostasis 1992;22:251-258.

26 Smith PS, Teutsch SM, Shaffer PA, Rolka H, Evatt B: Episodic versus prophylactic infusions for hemophilia A: a cost-effectiveness analysis. J Pediatr 1996;129:424-431.

27 The ESCHQoL Study, European Study of Clinical, Health Economic and Quality of Life Outcomes in Haemophilia treatment. www.eschqol.lmu.de/sys/ cgi/project.html.

28 Hobbins P, Anderson L, Cunningham N, Carnahan M, Park J, Denholm J, Newell C, McPherson J: Liberal eugenics: in defence of human enhancement $\mathrm{J}$ Bioethical Inquiry 2005;2:106-115. 